\title{
A Five Stage Environmental Exposure Assessment Strategy for Mixtures: Gasoline as a Case Study
}

\section{Supporting Information}

\section{Environmental Science \& Technology}

Karen L. Foster ${ }^{1}$, Don Mackay ${ }^{1}{ }^{*}$, Thomas F. Parkerton ${ }^{2}$, Eva Webster ${ }^{1}$, and Lynne Milford $^{1}$

${ }^{1}$ Canadian Environmental Modelling Centre, Trent University, 1600 West Bank Drive, Peterborough, ON, Canada, K9J 7B8. Phone: (705) 748-1011 x 1489; Fax: (705) 7481080; Email: dmackay@trentu.ca

\footnotetext{
${ }^{2}$ Toxicological and Environmental Sciences Division, ExxonMobil Biomedical Sciences Inc., 1545 Route 22 East Annandale, NJ, USA, 08801-0971

*Corresponding author
} 


\section{SECTION 1}

Table S1 Relative volume, mole and mass compositions in liquid and vapor phase of the gasoline component groups. When the composition based on one of these units is known, it can be converted to the other two using density and molar mass.

Deviation from the average is shown as the coefficient of variation.

\begin{tabular}{|c|c|c|c|c|c|c|c|}
\hline \multirow[b]{2}{*}{ Group \# } & \multicolumn{3}{|c|}{ Liquid } & \multicolumn{3}{|c|}{ Vapor } & \multirow{2}{*}{$\begin{array}{r}\text { Coefficient of } \\
\text { Variation \% }\end{array}$} \\
\hline & Volume \% & Mole \% & Mass \% & Volume \% & Mole \% & Mass \% & \\
\hline 1 & 5.04 & 6.20 & 3.92 & 36.74 & 40.45 & 33.78 & 13.6 \\
\hline 2 & 3.45 & 3.73 & 2.96 & 5.77 & 5.60 & 5.85 & 10.3 \\
\hline 3 & 2.35 & 2.25 & 2.12 & 1.17 & 1.00 & 1.25 & 25.5 \\
\hline 4 & 2.32 & 1.93 & 2.18 & 0.32 & 0.24 & 0.36 & 25.5 \\
\hline 5 & 22.31 & 22.48 & 19.39 & 34.22 & 30.88 & 35.14 & 7.1 \\
\hline 6 & 11.68 & 9.25 & 10.92 & 1.61 & 1.15 & 1.78 & 10.0 \\
\hline 7 & 1.82 & 1.19 & 1.78 & 0.06 & 0.03 & 0.07 & 20.6 \\
\hline 8 & 0.98 & 1.29 & 0.79 & 7.04 & 8.32 & 6.75 & 19.9 \\
\hline 9 & 2.86 & 3.03 & 2.61 & 3.11 & 2.95 & 3.36 & 10.7 \\
\hline 10 & 8.22 & 8.28 & 7.65 & 6.43 & 5.80 & 7.07 & 39.8 \\
\hline 11 & 1.91 & 2.19 & 1.95 & 1.08 & 1.11 & 1.31 & 15.0 \\
\hline 12 & 0.79 & 0.91 & 0.84 & 0.25 & 0.26 & 0.31 & 31.9 \\
\hline 13 & 2.25 & 2.14 & 2.36 & 0.35 & 0.30 & 0.43 & 21.2 \\
\hline 14 & 0.24 & 0.18 & 0.25 & 0.01 & 0.01 & 0.01 & 20.4 \\
\hline 15 & 0.17 & 0.23 & 0.19 & 0.13 & 0.15 & 0.16 & 14.3 \\
\hline 16 & 0.88 & 1.25 & 1.07 & 0.28 & 0.35 & 0.39 & 11.5 \\
\hline 17 & 10.40 & 12.30 & 12.43 & 0.97 & 1.02 & 1.37 & 8.0 \\
\hline 18 & 2.01 & 2.07 & 2.41 & 0.06 & 0.06 & 0.09 & 8.7 \\
\hline 19 & 10.44 & 10.64 & 12.40 & 0.30 & 0.27 & 0.42 & 7.6 \\
\hline 20 & 0.14 & 0.11 & 0.14 & 0.01 & 0.01 & 0.01 & 24.2 \\
\hline 21 & 9.29 & 8.00 & 11.10 & 0.06 & 0.05 & 0.09 & 8.2 \\
\hline 22 & 0.16 & 0.12 & 0.20 & 0.00013 & 0.00008 & 0.00019 & 25.2 \\
\hline 23 & 0.17 & 0.15 & 0.21 & 0.00005 & 0.00003 & 0.00006 & 14.9 \\
\hline 24 & 0.11 & 0.08 & 0.13 & 0.00003 & 0.00002 & 0.00004 & 21.2 \\
\hline
\end{tabular}




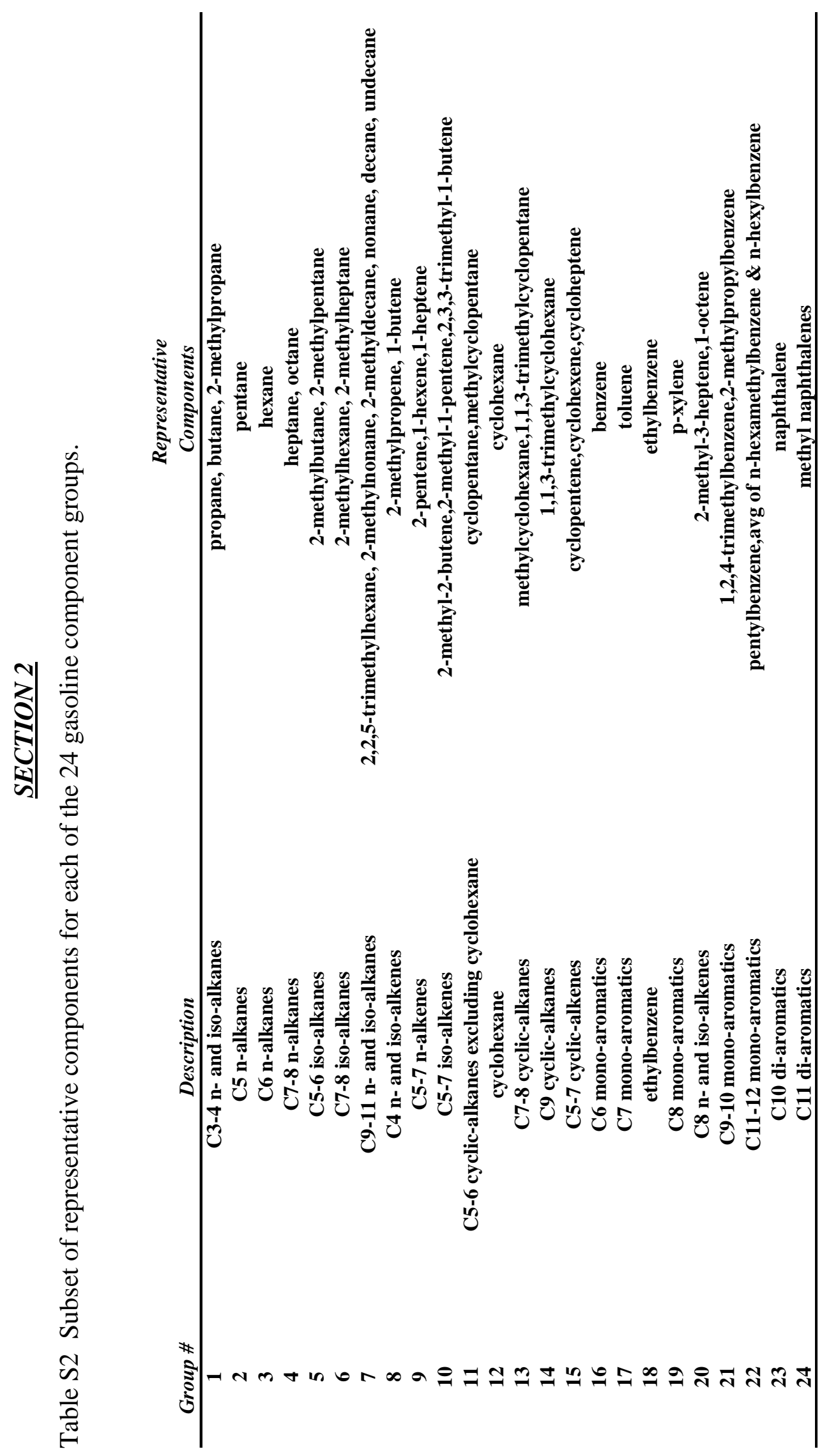

is 


\section{SECTION 3}

\section{Temperature Corrections}

Vapor pressure and $\mathrm{K}_{\mathrm{OW}}$ values were temperature corrected using the Clausius-Clapeyron equation:

$$
\ln \left(\frac{\mathrm{P}_{1}}{\mathrm{P}_{2}}\right)=\frac{\Delta \mathrm{H}_{\mathrm{Vap}}}{\mathrm{R}}\left(\frac{1}{\mathrm{~T}_{2}}-\frac{1}{\mathrm{~T}_{1}}\right)
$$

Where: $\quad \mathrm{P}_{1}=$ Initial vapor pressure $(\mathrm{Pa})$

$$
\mathrm{P}_{2}=\text { Final vapor pressure }(\mathrm{Pa})
$$

$$
\begin{aligned}
& \Delta \mathrm{H}_{\text {Vap }}=\text { Enthalpy of vaporization }\left(\mathrm{J} \mathrm{mol}^{-1}\right) \\
& \mathrm{R}=\text { Ideal gas law constant } 8.314 \mathrm{~J} \mathrm{~mol}^{-1} \mathrm{~K}^{-1} \\
& \mathrm{~T}_{1}=\text { Initial temperature }(298 \mathrm{~K}) \\
& \mathrm{T}_{2}=\text { Final temperature }(285 \mathrm{~K})
\end{aligned}
$$

Enthalpy of vaporization was calculated using Trouton's rule (1):

$$
\Delta \mathrm{H}_{\mathrm{Vap}}=87 \mathrm{~J} \mathrm{~mol}^{-1} \mathrm{~K}^{-1} \times \mathrm{T}_{\mathrm{B}}
$$

Where: $\quad \mathrm{T}_{\mathrm{B}}=$ Boiling point $(\mathrm{K})$

$\mathrm{K}_{\mathrm{OW}}$ values were temperature corrected using an enthalpy of phase transfer of $-20000 \mathrm{~J}$ $\mathrm{mol}^{-1}$, which is consistent with values measured by Lei et al. (2). Thus a decrease in temperature corresponds to a decrease in vapor pressure and an increase in $\mathrm{K}_{\mathrm{OW}}$. Water solubilities were not temperature corrected because they vary with temperature in a compound-specific manner, thus a unique temperature correction would be required for each group potentially introducing additional error. 
The Henry's law constants $(\mathrm{H})$, air-water partition coefficients $\left(\mathrm{K}_{\mathrm{AW}}\right)$ and octanol-air partition coefficients $\left(\mathrm{K}_{\mathrm{OA}}\right)$ were calculated from the temperature adjusted values for each group. $\mathrm{H}$ in units of $\mathrm{Pa} \mathrm{m}^{3} \mathrm{~mol}^{-1}$ was calculated as the vapor pressure in Pa divided by the water solubility in $\mathrm{mol} \mathrm{m}^{-3} . \mathrm{K}_{\mathrm{AW}}$ was calculated as $\mathrm{H}$ divided by the product of the gas constant $\left(8.314 \mathrm{~Pa} \mathrm{~m}^{3} \mathrm{~mol}^{-1} \mathrm{~K}^{-1}\right)$ and the temperature $(285 \mathrm{~K}) . \mathrm{K}_{\mathrm{OA}}$ was then calculated as the ratio between $\mathrm{K}_{\mathrm{OW}}$ and $\mathrm{K}_{\mathrm{AW}}$.

\section{SECTION 4}

Degradation Half-lives in Air

For degradation in air, three sets of values from predictive sources were compiled and are shown in Table S3. The TGD (3) and the QSAR-based model AOPWIN (version 1.90) (Syracuse Research Corporation, http://esc.syrres.com/interkow/estsoft.htm) from the EPIWIN suite of models, calculate the rate constant for degradation by reaction with hydroxyl radicals as:

$$
\mathrm{k}_{\mathrm{deg}-\text {-air }}=\mathrm{k}_{\mathrm{OH}} \mathrm{C}_{\mathrm{OH}} 3600
$$

Where: $\quad \mathrm{k}_{\text {deg-air }}=$ first-order rate constant for degradation in air $\left(\mathrm{h}^{-1}\right)$

$$
\begin{aligned}
\mathrm{k}_{\mathrm{OH}}= & \text { second order rate constant for degradation by reaction with } \mathrm{OH} \\
& \text { radicals }\left(\mathrm{cm}^{3} \text { molecule } \mathrm{s}^{-1}\right) \\
\mathrm{C}_{\mathrm{OH}}= & \text { concentration of } \mathrm{OH} \text { radicals in air }\left(\text { molecules } \mathrm{cm}^{-3}\right)
\end{aligned}
$$

The rate constants were then converted to half-lives in hours by multiplying the reciprocal of $k_{\text {deg-air }}$ by 0.693 . The difference between the TGD and AOPWIN predicted half-lives in air is that they assume different $\mathrm{OH}$ radical concentrations, the TGD assumes an average concentration of $5 \times 10^{5}$ molecules $\mathrm{cm}^{-3}$ whereas AOPWIN assumes $1.5 \times 10^{6}$ 
molecules $\mathrm{cm}^{-3}$. The TGD and AOPWIN half-lives in air in Table S3 were calculated using $\mathrm{k}_{\mathrm{OH}}$ values obtained for each representative component from AOPWIN and combined into single group values by taking the composition weighted average as was done for the physicochemical properties.

Table S3 Predicted half-lives in air in $\mathrm{h}$ from three sources.

\begin{tabular}{cccc} 
Group \# & TGD & EPIWIN & Mackay et al (2000) \\
\hline 1 & 182.10 & 51 & 17 \\
2 & 95.17 & 32 & 17 \\
3 & 70.53 & 24 & 17 \\
4 & 50.81 & 18 & \\
5 & 81.17 & 28 & 17 \\
6 & 50.86 & 17 & \\
7 & 36.67 & 17 & 5 \\
8 & 9.74 & 4 & \\
9 & 9.67 & 3 & 17 \\
10 & 5.97 & 2 & 17 \\
11 & 75.60 & 24 & 17 \\
12 & 45.41 & 15 & \\
13 & 50.46 & 15 & 5 \\
14 & 42.36 & 14 & 17 \\
15 & 6.30 & 2 & 17 \\
16 & 197.46 & 66 & 17 \\
17 & 73.67 & 25 & 17 \\
18 & 64.75 & 22 & 5 \\
19 & 59.12 & 16 & 17 \\
20 & 8.18 & 31 & \\
21 & 30.30 & 11 & 17 \\
22 & 15.95 & 9 & 17 \\
23 & 17.82 & 6 & \\
24 & 6.81 & 2 & \\
\hline
\end{tabular}

Estimated half-lives in air were also compiled, where available, for the representative components from Mackay et al. (4). These values are semi-quantitative, assigned to degradability classes of chemicals which were determined from an extensive literature review. 
The predicted values from these three sources are in fair agreement, most values being between 10 and 50 hours with higher values for the branched groups, lower molecular weight groups and group 16 (i.e. benzene). The assigned half-life values in air follow the trends visible in Table S3 between chemical classes and number of carbon atoms.

\section{SECTION 5}

\section{Biodegradation Half-Lives}

Table S4 shows predicted biodegradation half-lives for the component groups in STPs, water, soil and sediment from the TGD (3), BIOWIN (version 4.01) (Syracuse Research Corporation, http://esc.syrres.com/interkow/estsoft.htm) (a component of the EPIWIN suite of models) and Mackay et al. (4). The difference between predicted half-lives from the three sources is up to 2 orders of magnitude.

The TGD assigns a set of biodegradation half-lives to surface water, soil, sediment and STPs for chemicals within specified biodegradation classifications as summarized in Table S5. Biodegradation classifications for gasoline component groups are shown in Table S6. They were obtained from Parkerton (5) and were assigned by compiling standardized OECD ready biodegradation test results from a literature review and selecting the most applicable classification following the TGD methodology. Within a

given biodegradability classification, a consistent set of compartmental scaling factors are apparent between the degradation half-lives of 1 (STP) : 519 (water): 1038 (soil): 10380 (sediment), with the factors for soil and sediment increasing by one or two orders of magnitude as the solid-water partition coefficient $\left(\mathrm{K}_{\mathrm{p}}\right)$ increases. This methodology 
yields a set of biodegradation half-lives consistent between biodegradability

classifications and media and is particularly useful for chemicals where degradation halflife data are not available. However, it is preferable to use measured data when available, which are chemical-specific and eliminate possible generalization error.

In the case of gasoline, measured STP treatment efficiencies, i.e. the percentage of influent chemical load that evaporates, sorbes to sludge or degrades as distinct from the percentage that flows through the facility and is released as effluent, were compiled primarily from Bell et al. (6) and Monteith (7). STP half-lives were back-calculated from the measured treatabilities using the STP model (version 1.50) (Canadian Environmental Modelling Centre, http://www.trentu.ca/cemc). Groups for which treatability data were not available, i.e. alkanes and alkenes (groups 1 to 15), were assigned based on predicted half-lives in Table S4 and chemical structure. The treatabilities in Table S7 where estimated by STP using these half-lives.

There is continuing debate about where the biodegradation events occur in STPs. The STP model assigns a half-life to the mixed liquor and does not discriminate between sorbed and aqueous phase degradation kinetics. Whereas, other models such as SimpleTreat (8), assume that biodegradation occurs only in the dissolved or aqueous phase. This assumption is also invoked in deriving default TGD half-lives. For example, two hydrocarbons with similar overall mixed liquor half-lives, but differing in hydrophobicity $\left(\mathrm{K}_{\mathrm{OW}}\right)$ will be attributed the same half-life in the STP model but different half-lives in other models. Using the STP model simplifies, we believe, this concern. It 
is expected that both methods would yield similar biodegradability trends between chemicals but that the STP model predicted half-lives would be longer and thus more conservative.

A revised set of compartmental scaling factors was selected to translate the empirically derived STP half-lives into a set of predicted water, soil and sediment half-lives for all gasoline groups: 1 (STP) : 150 (water) : 450 (soil) : 1350 (sediment). Consideration was given to semi-quantitative data on primary biodegradation rates in water, soil and sediment from Mackay et al. (4), the TGD (3), as well as expert judgments of biodegradability via BIOWIN QSAR-based predictions. These scaling factors differ from the default TGD values in part because of the different half-life definitions and also because they are specific to gasoline hydrocarbons. Such factors may not apply to nonhydrocarbons or component groups of other mixtures. 


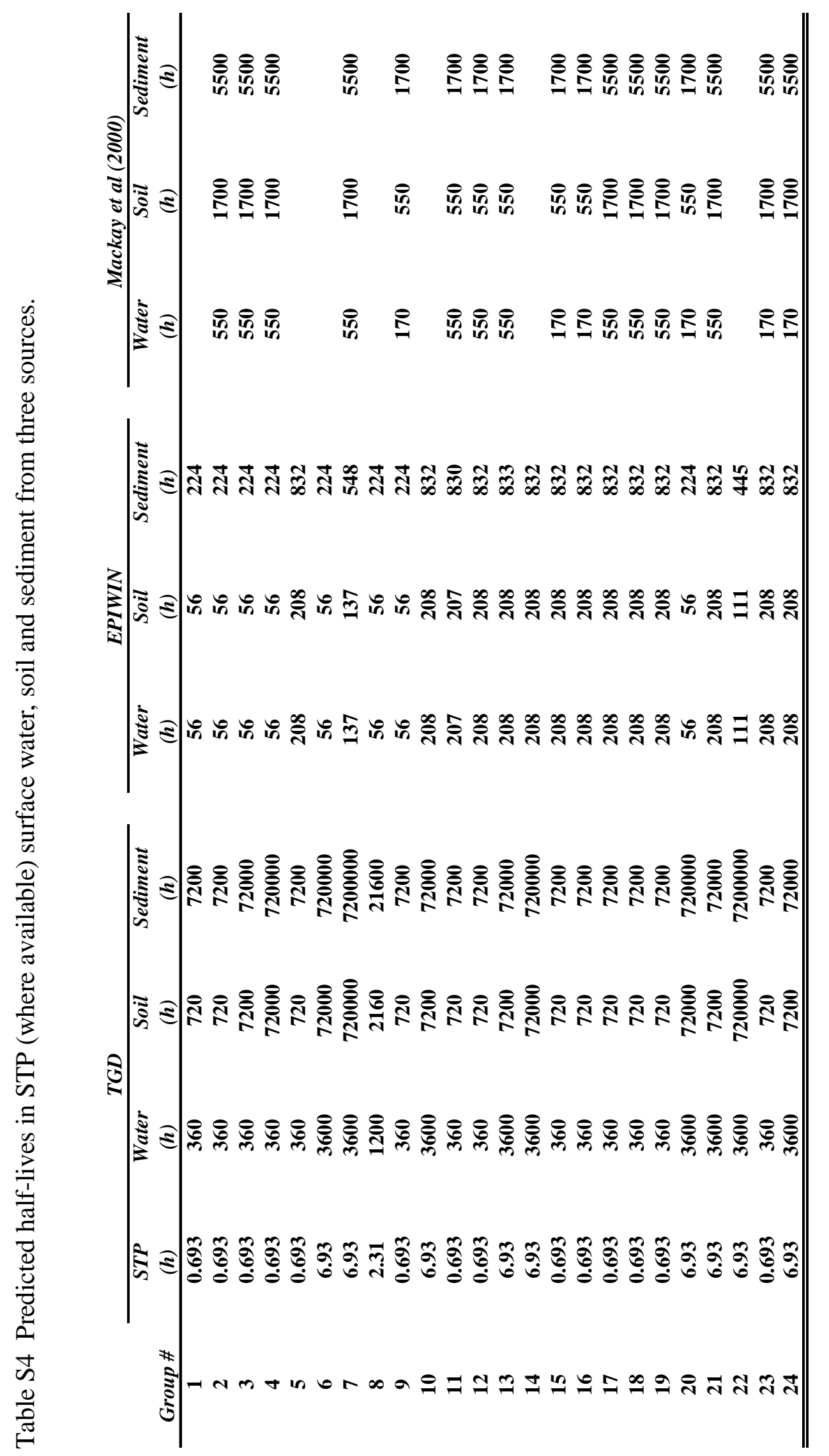




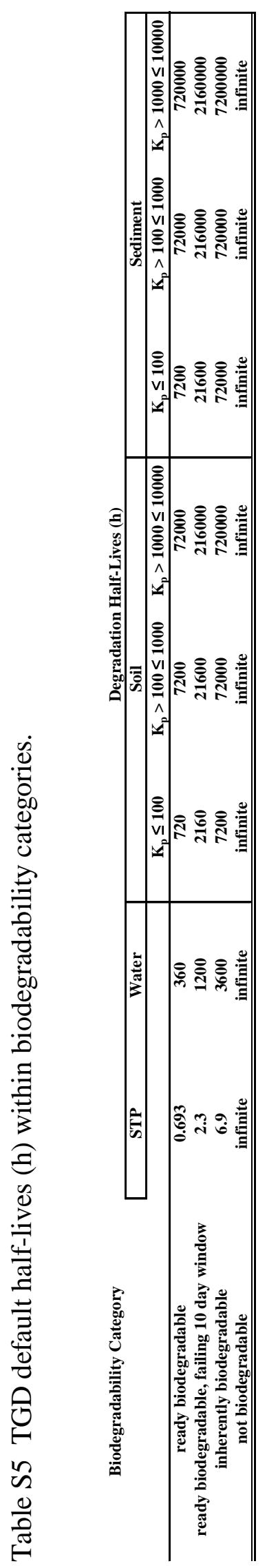

$\bar{\prime}$ 
Table S6 Biodegradability classifications.

\begin{tabular}{cc} 
Group \# & \\
\hline 1 & Ready Biodegradable \& meets 10 d window \\
2 & Ready Biodegradable \& meets 10 d window \\
3 & Ready Biodegradable \& meets 10 d window \\
4 & Ready Biodegradable \& meets 10 d window \\
5 & Ready Biodegradable \& meets 10 d window \\
6 & Inherently Biodegradable \\
7 & Inherently Biodegradable \\
8 & Ready Biodegradable doesn't meet 10 d window \\
9 & Ready Biodegradable \& meets 10 d window \\
10 & Inherently Biodegradable \\
11 & Ready Biodegradable \& meets 10 d window \\
12 & Ready Biodegradable \& meets 10 d window \\
13 & Inherently Biodegradable \\
14 & Inherently Biodegradable \\
15 & Ready Biodegradable \& meets 10 d window \\
16 & Ready Biodegradable \& meets 10 d window \\
17 & Ready Biodegradable \& meets 10 d window \\
18 & Ready Biodegradable \& meets 10 d window \\
19 & Ready Biodegradable \& meets 10 d window \\
20 & Inherently Biodegradable \\
21 & Inherently Biodegradable \\
22 & Inherently Biodegradable \\
23 & Inherently Biodegradable \\
24 & Ready Biodegradable \& meets 10 d window \\
\hline \hline
\end{tabular}


Table S7 STP treatabilities as estimated by the STP model using selected half-lives.

\begin{tabular}{|c|c|c|c|c|}
\hline Group \# & $\begin{array}{c}\text { Volatilization } \\
(\%) \\
\end{array}$ & $\begin{array}{c}\text { Effluent } \\
(\%)\end{array}$ & $\begin{array}{c}\text { Sludge } \\
(\%)\end{array}$ & $\begin{array}{c}\text { Biodegradation } \\
(\%)\end{array}$ \\
\hline 1 & 86.7 & 0.0692 & 2.3 & 10.9 \\
\hline 2 & 62.8 & 0.114 & 6.13 & 31 \\
\hline 3 & 36.4 & 0.052 & 13.9 & 49.6 \\
\hline 4 & 11.2 & 0.0199 & 20.4 & 68.4 \\
\hline 5 & 80.4 & 0.12 & 1.15 & 18.3 \\
\hline 6 & 56.7 & 0.0465 & 15.4 & 27.8 \\
\hline 7 & 19.6 & 0.041 & 29.3 & 51 \\
\hline 8 & 85.4 & 0.271 & 0.938 & 13.4 \\
\hline 9 & 70.4 & 0.599 & 2.06 & 27 \\
\hline 10 & 76.4 & 0.708 & 4.3 & 18.5 \\
\hline 11 & 59.2 & 0.494 & 4.87 & 35.4 \\
\hline 12 & 65.5 & 0.937 & 7.08 & 26.5 \\
\hline 13 & 53.2 & 0.317 & 14.2 & 32.3 \\
\hline 14 & 32.5 & 0.106 & 23.8 & 43.7 \\
\hline 15 & 53.6 & 2.02 & 1.59 & 42.8 \\
\hline 16 & 17.4 & 7.24 & 0.744 & 74.6 \\
\hline 17 & 16.6 & 6.06 & 1.75 & 75.6 \\
\hline 18 & 14.5 & 4.27 & 3.85 & 77.4 \\
\hline 19 & 9.82 & 4.32 & 4.22 & 81.6 \\
\hline 20 & 32.8 & 0.232 & 21.5 & 45.4 \\
\hline 21 & 8.63 & 2.89 & 12.5 & 76 \\
\hline 22 & 0.597 & 0.146 & 29.5 & 69.8 \\
\hline 23 & 1.6 & 6.98 & 6.71 & 84.7 \\
\hline 24 & 0.82 & 2.74 & 14 & 82.5 \\
\hline
\end{tabular}




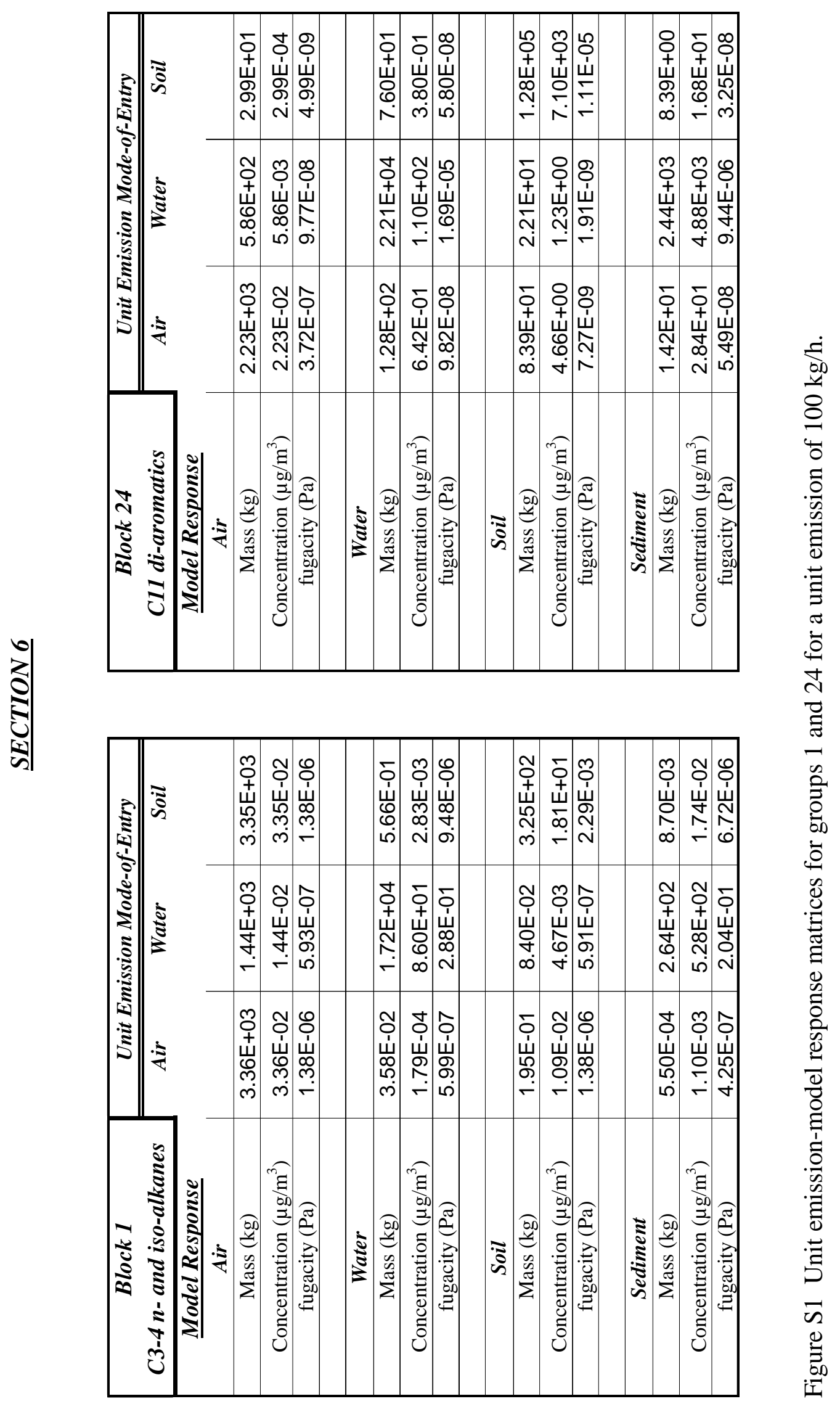




\section{REFERENCES}

(1) Hand, C.W. General Chemistry. Harcourt Brace \& Company: Orlando, FL, 1994.

(2) Lei, Y.D.; Wania, F.; Shiu, W.Y.; Boocock, D.G.B. HPLC-based method for estimating the temperature dependence of n-octanol-water partition coefficients.

J. Chem. Eng. Data. 2000, 45, 738-742.

(3) EC (European Commission). Technical guidance documents in support of Directive 93/67/EEC on risk assessment of new notified substances and Regulation No. 1488/94 on risk assessment of existing substances. Office for Official Publications of the European Community, Luxembourg, 1996.

(4) Mackay, D.; Shiu, W.Y.; Ma, K.C. Physical-Chemical Properties and Environmental Fate and Degradation Handbook (CD-ROM). CRC Press LLC: Boca Raton, FL, 2000.

(5) Parkerton, T.F. Personal communication, 2003.

(6) Bell, J.; Melcer, H.; Monteith, H.; Osinga, I.; Steele, P. Water Environ. Res. 1993, 65, 708-716.

(7) Monteith, H. Fluctuations of Trace Contaminants in Sewage Treatment Plants; Monograph Series 1 On Advances in Water Pollution Research \& Technology. Canadian Association on Water Pollution Research \& Control: Burlington, ON, 1987.

(8) van de Meent, D. SimpleBox:a generic multi-media fate evaluation model. Report 6727200001, National Institute of Public Health and the Environment (RIVM), Bilthoven, The Netherlands, 1993. 